\title{
FDA turns down moratorium demand on xenotransplants
}

[WASHINGTON] The US Food and Drug Administration (FDA) last week resisted calls that it should declare a moratorium on clinical trials of xenotransplantation on the grounds that more time is needed to find out about the potential risks.

The call for a moratorium has come from Fritz Bach, a xenotransplant scientist at Harvard Medical School, and eight coauthors, in an article to appear in the February issue of Nature Medicine (see Nature Medicine 4, 141-144; 1998 and Nature 391, 326; 1998).

At a two-day meeting convened at the National Institutes of Health (NIH) by the US Public Health Service and attended by leading administrators and scientists, Michael Friedman, acting FDA commissioner, said the call was a "highly valuable" part of the public debate. But he added: "We believe that it's important to set up a framework to responsibly conduct research. And that's what we're endeavouring to do."

The FDA wants to continue cautiously with trials with careful safeguards and strict supervision, and this position was reflected in the views of many experts at the meeting. "The field requires the beginning of well designed, well controlled clinical trials," said Daniel Salomon, an immunologist at the Scripps Research Institute in La Jolla, California, and member of the board of the American Society of Transplant Physicians.

Salomon and others argued that the call for a moratorium was untimely, and demonstrated a lack of awareness of the public debate and regulatory process that has taken place over the past four years. Another critic was David Onions, professor of veterinary pathology at the University of Glasgow and author of a paper showing that pigs harbour endogenous retroviruses that can infect human cells in vitro.

The Bach article "was written as if none of us had ever thought of these issues," said Onions, who sits on an FDA advisory subcommittee on xenotransplantation, and who opposes a moratorium. "It was as if [those calling for a moratorium] were unaware of what has happened."

But some at the meeting supported Bach and his coauthors, who want a moratorium on clinical trials while a national committee of "broadly concerned citizens from many walks oflife" grapples with the risk issues. Alix Fano, of the Campaign for Responsible Transplantation, based in New York, demanded: "Who will beheld accountable if and when a zoonotic virus is spread to the human population?" Friedman acknowledged: "Those are difficult questions."

Bach said he was not convinced by FDA officials during the meeting that a 'transparent' process involving the public was important to the agency. The FDA and other regulators had done a "very good job" of drawing up regulations based on technical considerations. But he added: "I am not sure they are hearing the need for ethics to precede the technical discussion. And they have not focused on [the public involvement that] I and my coauthors feel should come first. That leaves me with great disquiet."

Onions, Salomon and others contend that, in eight meetings over the past four years, US authorities have publicly debated the pros and cons of xenotransplantation, including the ethical issues. Guidelines for those engaging in xenotransplantation, issued by the Public Health Service in September 1996, and revised in a stricter form to be issued this year, reflect those years of careful debate, they say.

The revised guidelines, first described publicly at last week's meeting but not final until published later this year, bring all xenotransplant trials under FDA's oversight, rather than that of local institutional review boards. They include the setting up of a xenotransplantation registry and a central archive to house biological specimens for at least 50 years. FDA officials estimate the cost of the registry at $\$ 250,000$ to $\$ 300,000$ a year, and $\$ 1$ million a year for the archive.

The guidelines also suggest the creation of a National Advisory Committee. Mary Groesch, an NIH official who addressed the meeting on behalf of a Department of Health and Human Services committee on xenotransplantation, said that this should function much like the Recombinant DNA Advisory Committee, which gave public scrutiny to gene therapy protocols.

But Kathryn Zoon, director of the FDA's Center for Biologics Evaluation and Research, said the agency is still developing its policy on how much data about proposed clinical trials would be made public before trials begin. She said the agency intends to make "a select subset" of information available "that will enable public knowledge of preclinical and clinical research".

Jonathan Allan, a virologist at the Southwest Foundation for Biomedical Research in San Antonio, Texas, attacked the revised guidelines for failing to ban the use of nonhuman primates as donors or to establish stricter, separate criteria for their use.

Allan told the meeting that the health service has "ignored" a substantial risk, because the infectious disease risks to humans in the use of primate donors are far greater than those of pigs.

MeredithWadman

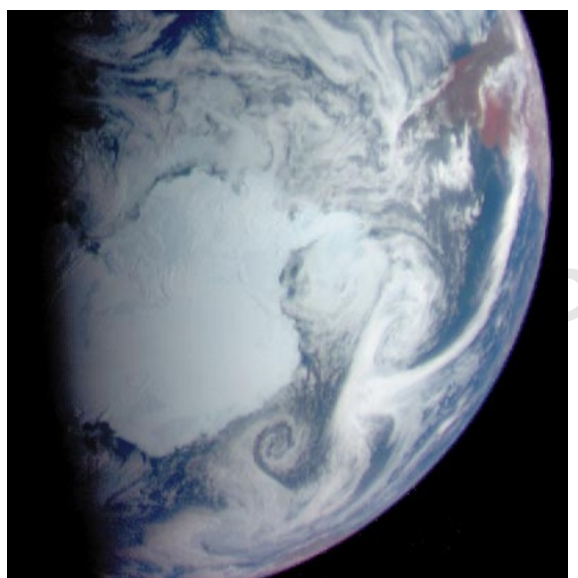

NEAR view: a composite image of Antarctica, taken by the spacecraft's multi-spectral imager.

\section{Earth today, Eros in a year's time, for asteroid spacecraft}

[WASHINGTON] The NEAR (Near Earth Asteroid Rendezvous) spacecraft swung past Earth last week in a manoeuvre that puts it on target for an encounter with asteroid 433 Eros a year from now.

In addition to using Earth's gravity to change the spacecraft's trajectory, the swingby gave project managers the chance to calibrate the craft's instruments by pointing them at their planet of origin.

Among the pictures snapped by the craft's Multi-Spectral Imager were a 'family portrait' of the Earth and Moon, and views of Antarctica and the surrounding ocean (above) taken after the closest Earth approach, which occurred 336 miles above southwest Iran. Sun glinting off NEAR's solar panels made it visible to observers throughout the world as a steady light moving across the sky.

The spacecraft is expected to return its first, dot-like images of Eros next summer. On 20 December it will begin firing braking rockets in anticipation of the rendezvous, and will enter orbit around the 25-mile-long asteroid on 10 January 1999 at an altitude of $1,000 \mathrm{~km}$ above the surface.

The orbit will then drop to as low as $35 \mathrm{~km}$ during an intensive year-long study, which will include mapping the surface at high resolution and characterizing the asteroid's bulk properties, mineral composition, geology and magnetic field.

The mission will end on 6 February 2000 with a slow 'controlled crash' on to the asteroid's surface.

NEAR follows last year's Mars Pathfinder as the second in the US space agency NASA's Discovery series of low-cost planetary missions.

Built and operated by Johns Hopkins University's Applied Physics Laboratory, it is the first planetary mission to be managed from outside the agency. Tony Reichhardt 